\title{
Chromobacterium violaceum Infection in a Free-ranging Howler Monkey in Costa Rica
}

\begin{abstract}
Mario Baldi, ${ }^{1,2}$ Juan A. Morales, ${ }^{1}$ Giovanna Hernández, ${ }^{1}$ Mauricio Jiménez, ${ }^{1}$ Alejandro Alfaro, ${ }^{1}$ and Elias Barquero-Calvo ${ }^{1}{ }^{1}$ Tropical Diseases Research Program, School of Veterinary Medicine, Universidad Nacional de Costa Rica, Heredia, Apartado Postal 86-3000, Costa Rica; ${ }^{2}$ Corresponding author (email: mbaldi@medvet.una.ac.cr)
\end{abstract}

ABSTRACT: Chromobacterium violaceum is a gram-negative saprobe bacterium that is a rare opportunistic pathogen in mammals. There are numerous reports in humans including fatalities, but no record exists in free-ranging nonhuman primates. Here we report an infection by $C$. violaceum in a wild adult male howler monkey (Alouatta palliata) captured at Ballena Marine National Park, in southwestern Costa Rica. The individual had severe skin lesions over its extremities; gross findings included multiple skin ulcers, white foci in liver, and lymphoid hyperplasia. Histologic results included deep dermatitis with presence of necrotic epithelial cells where clusters of coccoid-shaped bacteria were detected. In the liver, numerous neutrophils forming microabscesses, telangiectasia, and focal necrotic areas were observed. Necrotic liver tissue sampled for bacteriologic culture resulted in the isolation of C. violaceum. We could not ascertain the source or mechanism of infection in this case, although infection through skin microabrasions is suspected. To the best of our knowledge, this is the first report for this pathogen in a wild, nonhuman primate. This report also draws attention to this infectious agent as a potential emerging wildlife disease and consideration should be paid by regional veterinary and epidemiologic vigilance services.

Key words: Bacterial infection, Chromobacterium violaceum, opportunistic pathogen, wild primate.

Chromobacterium violaceum is a gramnegative bacterium commonly isolated from soil and water in tropical and subtropical environments that has been associated with rare, opportunistic infections in mammals, including humans (Strong, 1944; Alves De Brito et al., 2004). Although C. violaceum has been characterized as a saprobe, it is also well known for its ability to act as an infectious agent (Groves et al., 1969; Kalter, 1989;
Dyer et al., 2000; Crosse et al., 2006). Infection generally occurs through abrasions or by ingestion of contaminated water or soil (Lee et al., 1999; Dyer et al., 2000; De Siqueira et al., 2005; Crosse et al., 2006). The disease is systemic, with the development of septicemia, skin ulcers, and pulmonary and liver abscesses (Alves De Brito et al., 2004); septic shock and multiple organ failure commonly result in death of infected individuals (Groves et al., 1969; Lee et al., 1999; Dyer et al., 2000; De Siqueira et al., 2005; Crosse et al., 2006). The majority of human cases reported have been associated with immunocompromised patients (De Siqueira et al., 2005; Kim et al., 2005; Martinez et al., 2000). This report details the first documented case of chromobacteriosis in a wild, free ranging nonhuman primate, a neotropical howler monkey (Alouatta palliata).

A living adult male A. palliata was received for medical evaluation at the Pathology Department of the School of Veterinary Medicine at the National University of Costa Rica on January 25, 2004. The individual had been found 1 day before by National Wildlife Service officials on the upland section of Ballena Marine National Park $\left(9^{\circ} 09^{\prime} \mathrm{N}, 83^{\circ} 44^{\prime} \mathrm{W}\right)$, on the country's southern Pacific coast. At the time of capture, the specimen was on the ground, displayed ataxia, lack of coordination, and signs of emaciation. Due to its condition and low weight (6 $\mathrm{kg}$ ), the animal was euthanatized with sodium thiopental (Biochemie, GmbH. Vienna, Austria) and a necropsy was carried out immediately thereafter. 


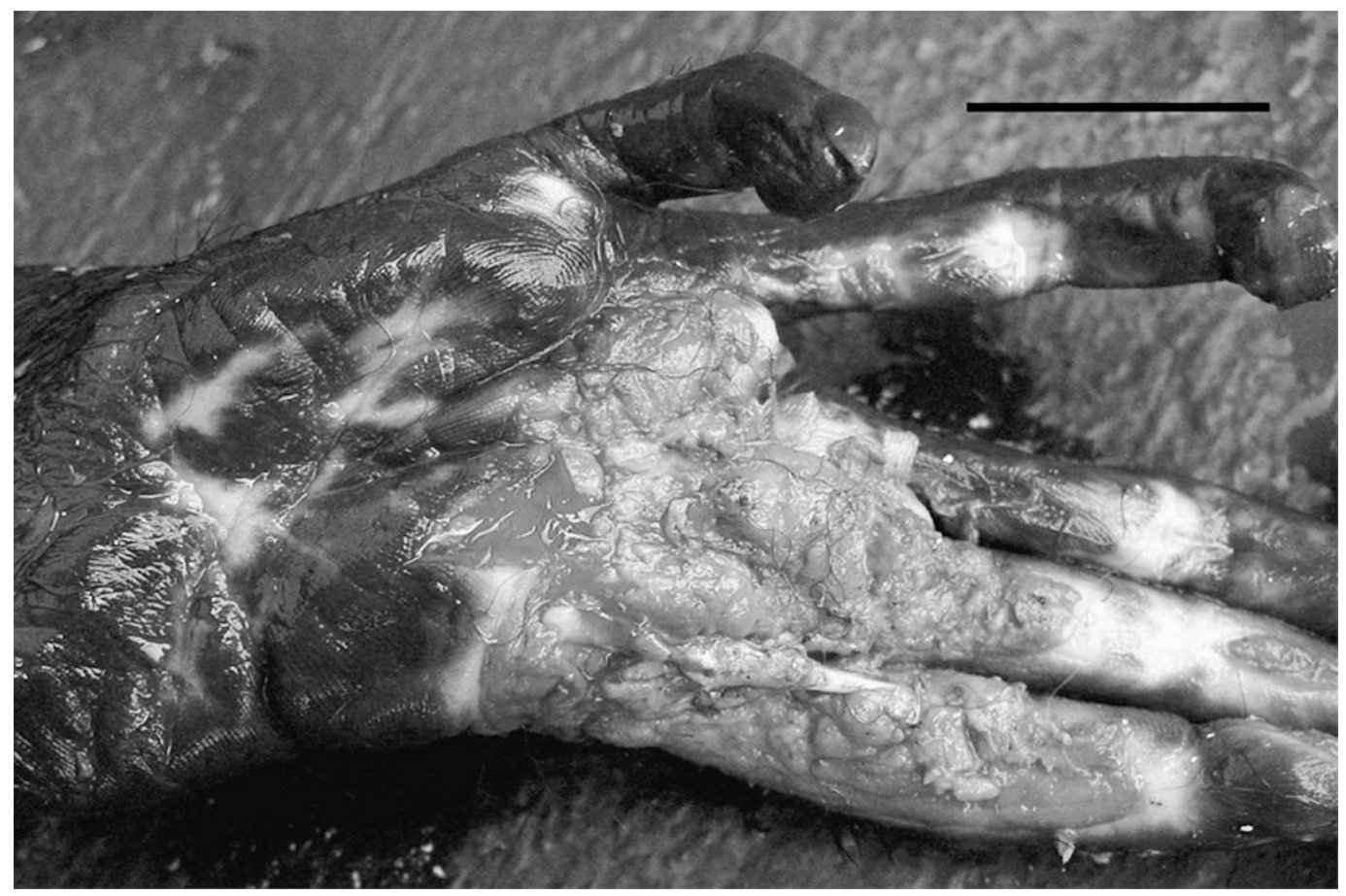

Figure 1. Skin with necrotic ulcerative dermatitis of upper limb. Bar $=3 \mathrm{~cm}$.

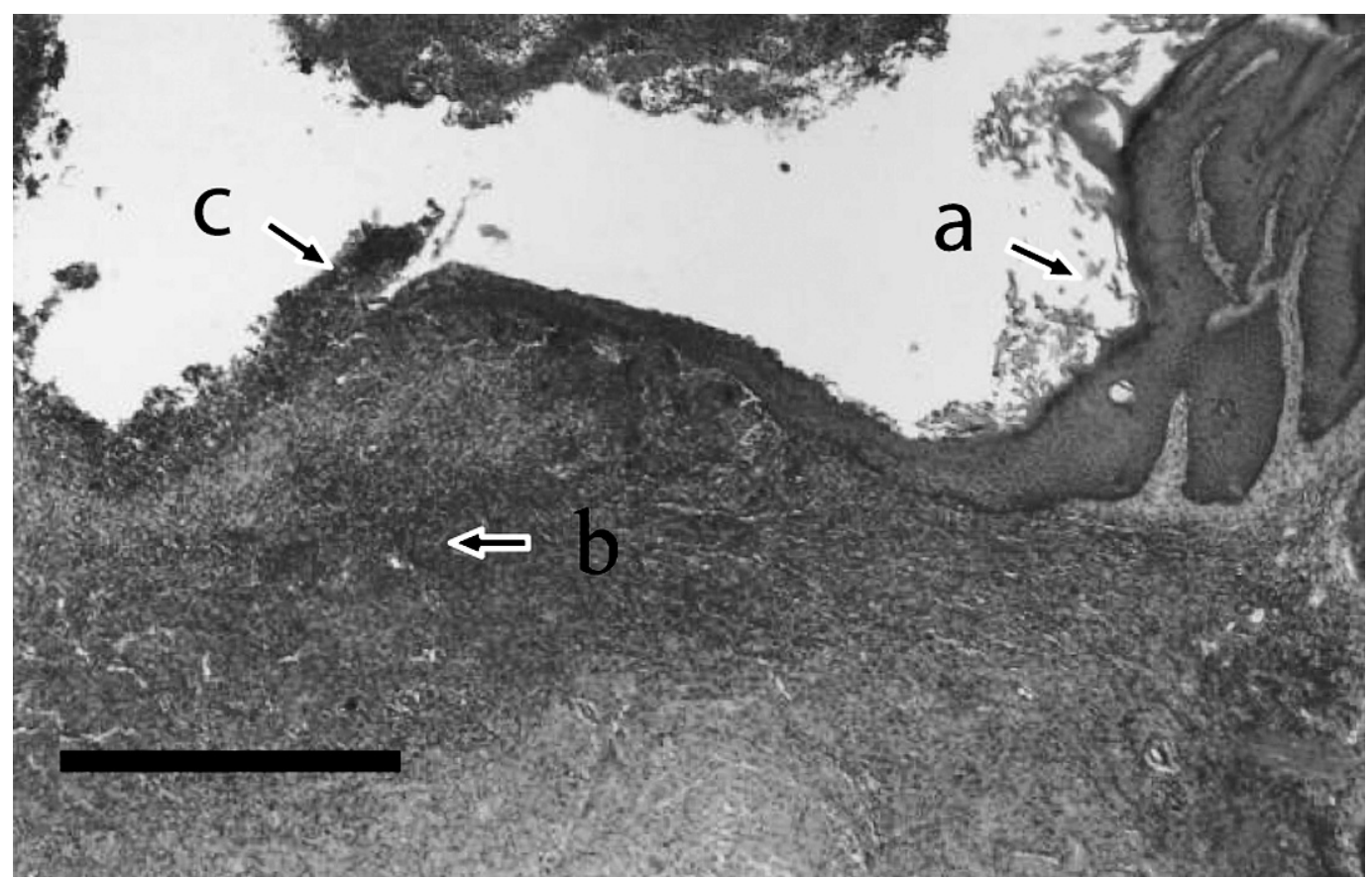

FIgURE 2. Skin section showing (a) normal epithelium, (b) massive cellular infiltration, and (c) necrotic ulcerative dermatitis. Bar $=500 \mu \mathrm{m}$. 


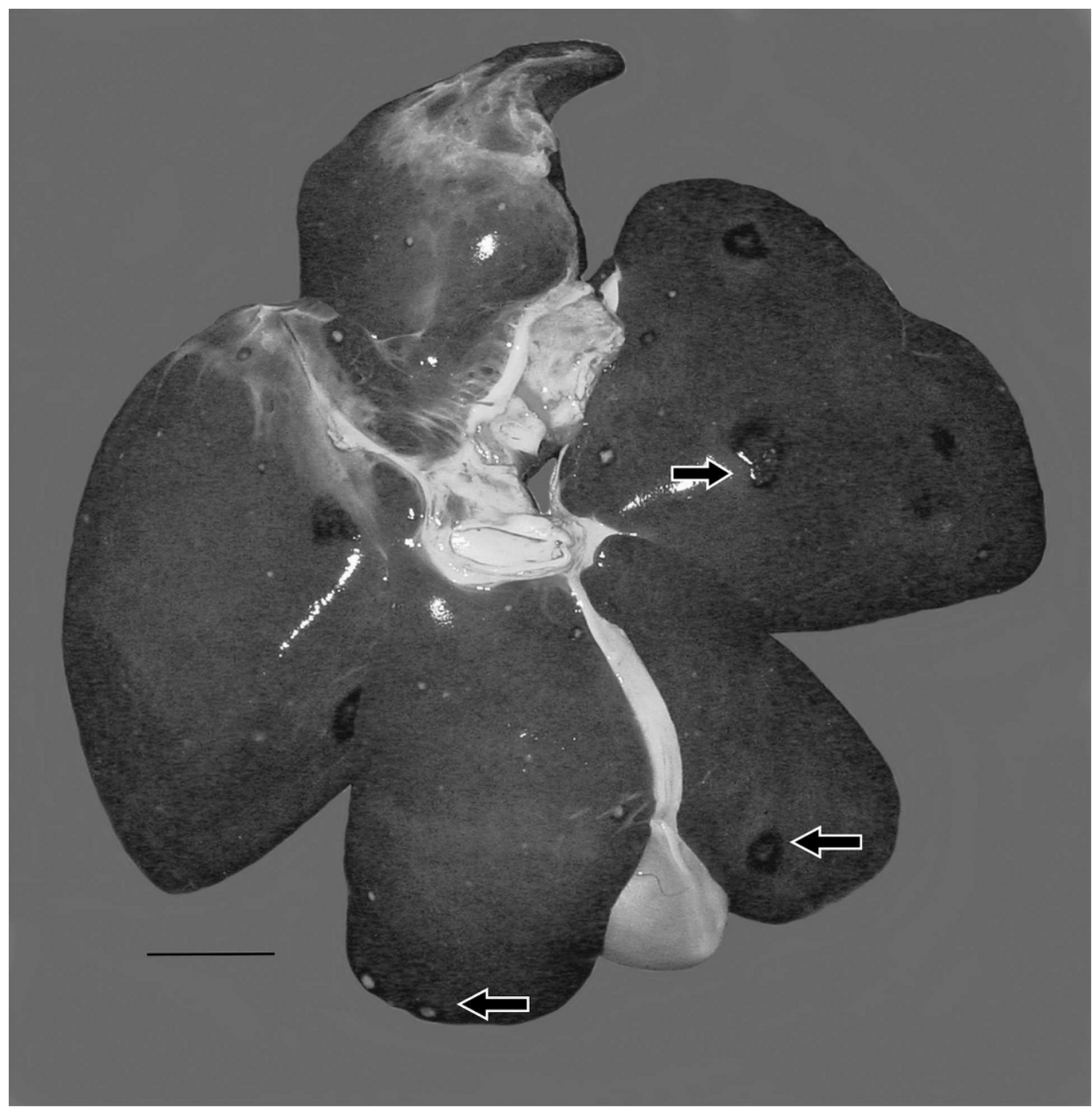

Figure 3. Liver showing diffuse foci of white spots surrounded by hyperemia. Bar $=1 \mathrm{~cm}$.

Gross lesions observed during necropsy revealed loss of epidermis and ulceration with necrotic areas surrounded by a yellowish substance in mouth, tail, and palms and fingers of upper limbs (Fig. 1). The liver had multiple focal white foci, 0.2 to $2 \mathrm{~cm}$ in diameter, which were surrounded by red halos on the liver capsule and in the parenchyma (Fig. 2). Generalized enlargement of the lymph nodes was observed as well. Other organs did not have any obvious alterations or lesions.

Skin, liver, and lymphoid tissue samples were fixed in $10 \%$ neutral buffered formalin for histologic examination following the standard procedures, which included cutting sections at $3 \mu \mathrm{m}$ and staining with hematoxylin and eosin (Aughey and Frye, 2001). During histopathologic examination, severe, deep ulcerative dermatitis and necrosis in multiple locations was observed. These were characterized by massive neutrophil infiltration, and lesser numbers of macrophages, plasma cells, and lymphocytes (Fig. 3). Tissue granulation was observed on the 


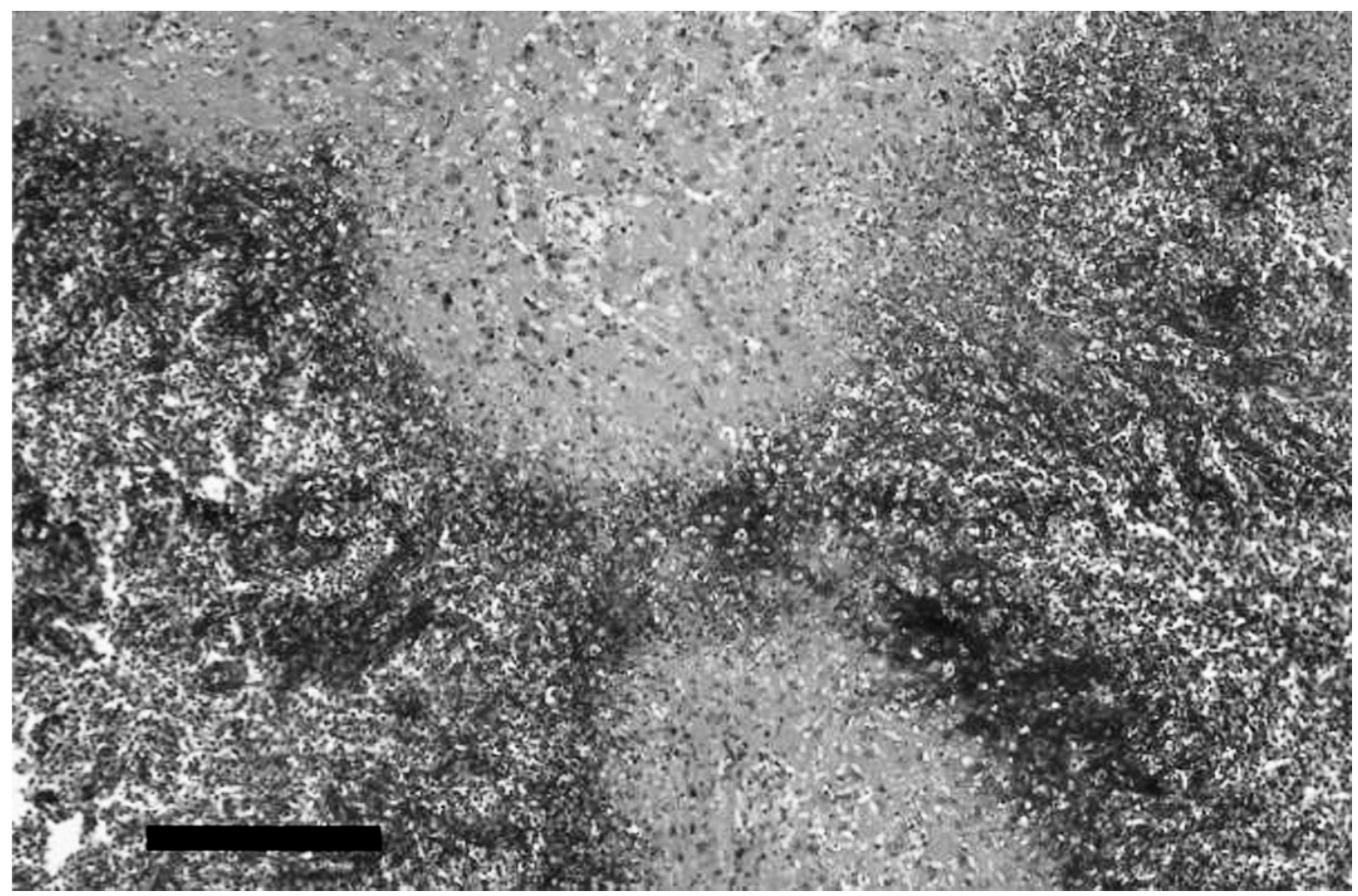

FIgURE 4. Liver section showing necrotic area with massive infiltration of neutrophils. Bar $=100 \mu \mathrm{m}$.

deep edge of skin abrasions. Clusters of gram-negative, coccoid-shaped bacteria, telangiectasia, and focal necrotic areas were observed on skin sections. In the liver, white foci were evident between the liver capsule and parenchyma. Neutrophil infiltration formed microabscesses, which were surrounded by hyperemia and mononuclear cells. Several necrotic foci within the portal space were also observed (Fig. 4). Lymphatic tissue had an increased number of mononuclear cells compatible with hyperplasia.

Direct gram stain impressions from liver samples confirmed the presence of gram-negative cocobacilli. Liver samples were inoculated in MacConkey and blood agar plates for aerobic bacteriologic culture and incubated at $35 \mathrm{C}$ for $24 \mathrm{hr}$. No anaerobic cultures were performed. Smooth and violet-pigmented, homogeneous colonies developed in pure culture on both agars. These were subjected to biochemical profiling with the API $20 \mathrm{NE}$ system (bioMérieux, Marcy l'Etoile,
France) and identified as C. violaceum (1-1-5-2-5-5-4) with 99.3\% accuracy.

The pathologic profile of the case here described was congruent with previous reports of infection by C. violaceum (Lee et al., 1999; Dyer et al., 2000; Martinez et al., 2000; Alves De Brito et al., 2004; Kim et al. 2005), and based on the evidence presented above we implicate this pathogen as the etiologic agent. Postmortem overgrowth was ruled out, because the necropsy was performed immediately after euthanasia. We could not ascertain the source or mechanism of infection, although infection by contact through skin microabrasions with contaminated soil or water in the natural environment is suspected. Howler monkeys are nonstrict arboricolous, as they have been reported to come to the ground to tap ground-level water resources and to swim across water bodies (Kellen and Stouffer, 1989; Wainwright, 2002). To the best of our knowledge, this is the first reported case of this pathogen in a wild, free ranging nonhu- 
man primate. The only previous reports come from captive primates in zoos and research laboratories, where affected individuals had hepatic abscess and skin lesions similar to those described here (Groves et al., 1969; McClure and Chang, Kalter, 1989; Konegay et al. 1991).

Currently, there is no formal registry of similar cases in Costa Rica. However, residents from the vicinity of Ballena Marine National Park have given informal reports to park officials that describe other wild mammals presenting external symptoms similar to those described here. It is advisable that attention be given to this infectious agent as a potential emerging wildlife disease by local veterinary and epidemiologic vigilance services, especially in areas where humans may come in contact with infected animals.

\section{LITERATURE CITED}

Aughey, E., And F. Frye. 2001. Comparative veterinary histology with clinical correlates. Manson Publishing Ltd., London, UK, p. 320.

Alves de Brito, C. F., C. M. Carvalho, F. R. Santos, R. T. Gazinell, S. C. Oliveira, V. Azevedo, and M. N. Teixeira. 2004. Chromobacterium violaceum genome: molecular mechanisms associated with pathogenicity. Genetic and Molecular Research 3: 148-161.

Crosse, A. P., K. Soares, J. L. Wheeler, K. L. Cooker, C. A. Adin, J. J. O'Kelly, and J. K. LEvy. 2006. Chromobacterium violaceum infection in two dogs. Journal of the American Animal Hospital Association 42: 154-159.

De Siqueira, I. C., J. Dias, H. Ruf, E. A. Ramos, E. A. Pires M., A. Rolim, L. Jabur, L. Vasconcelos, AND C. Silvany. 2005. Chromobacterium violaceum in siblings, Brazil. Emerging Infectious Diseases 11: 1443-1445.

Dyer, N. W., D. F. Krogh, R. Devold, S. L. Wilson,
AND D. G. White. 2000. Chromobacteriosis in a Chinese red panda (Ailurus fulgens styani). Journal of Veterinary Diagnostic Investigation 12: 177-179.

Groves, M. G., J. M. Strauss, J. D. Abbas, and C. E. DAVIS. 1969. Natural infection of Gibbons with a bacterium producing violet pigment (Chromobacterium violaceum). Journal of Infectious Diseases 120: 605-610.

Kalter, S. S. 1989. Infectious diseases of nonhuman primates in a zoo setting. Zoo Biology Supplement 1: 61-76.

Kellen, G. A., and P. C. Stouffer. 1989. Use of a ground water source by mantled howler monkey (Alouatta palliata). Biotropica 21: 380.

Kim, H. M., H. J. Lee, T. J. Suh, B. S. Chang, and K. S. Сно. 2005. A case of Chromobacterium infection after car accident in Korea. Yonsei Medical Journal 47: 700-702.

Kornegay, R. W., G. Pirie, C. C. Brown, and J. C. Newton. 1991. Chromobacteriosis (Chromobacterium violaceum) in three colobus monkeys (Colobus polykomos). Journal of Zoo and Wildlife Medicine 22: 476-484.

Lee, J., J. S. Kim, C. H. Nahm, J. W. Chio, S. H. Pai, K. H. Moon, K. Lee, and Y. Chong. 1999. Two cases of Chromobacterium violaceum infection after injury in a subtropical region. Journal of Clinical Microbiology 37: 2068-2070.

Martinez, R., M. A. Velludo, V. R. Dos Santos, And P. V. Dinamarci. 2000. Chromobacterium violaceum infection in Brazil. A case report. Revista do Instituto de Medicina Tropical de Sao Paulo 42: 111-113.

McClure, H. M., And J. Chang. 1976. Chromobacterium violaceum infection in a nonhuman primate (Macaca assamensis). Labotatory Animal Science 26: 807-810.

Strong, F. M. 1944. Isolation of violacein. Science 100: 287.

Wainwright, M. 2002. The natural history of Costa Rican mammals. Zona Tropical, Miami, Florida, p. 384 .

Received for publication 2 October 2007. 